\title{
Conditional antecedents as polar free relatives*
}

\author{
Gregor Williamson \\ University College London
}

\begin{abstract}
This short paper outlines a transparent syntax-semantics mapping for the internal structure of a conditional if-clause. Specifically, we show that the conditional-interrogative link (Starr 2009, 2014) is straightforwardly accounted for on the if-clause-as-restrictor analysis of conditionals (Lewis 1975; Kratzer 1981, $1986,2012)$ when if-clauses are treated as polar free relatives.
\end{abstract}

Keywords: conditionals, if-clauses, polar questions, free relatives

\section{Introduction}

It has long been noted that conditional clauses and (embedded) polar questions are morphologically similar, if not identical, in many of the world's languages, with English being one such language. In (1a), the if-clause marks the antecedent of a canonical conditional, while in (1b) the if-clause serves the role of an embedded polar question.

(1) a. [If John left], Mary will be happy

b. Mary knows [if John left].

Besides canonical indicative conditionals, English also has the ability to form counterfactual conditionals by Subject-Auxiliary inversion (i.e., T-to-C movement) (Iatridou \& Embick 1994), as can be observed in (2a). Similarly, this type of inversion is found in polar questions in root clauses $(2 b)$.

(2) a. [Had John left], Mary would be happy

b. [Had John left] (by then)?

Besides English, homophony between conditional and interrogative markers is also found in languages as diverse as Albanian and Greek (Iatridou \& Zeijlstra 2015), Romance (see Kayne 1991 for French and Italian), Slavic languages such

* We thank Yasu Sudo, Sabine Iatridou, Pietro Baggio, Angelika Kratzer, Justin Khoo, Klaus Abels, Stephen Colvin, as well as audiences of UCL Syntax Reading Group, MIT LFRG, and the poster session at SALT29 for helpful feedback and discussion. 
as Serbo-Croatian (Arsenijević 2009), and Bulgarian (Bhatt \& Pancheva 2006), Papuan Hua (Haiman 1978), Mayan Tzotzil (Haiman 1978 citing Cowan 1969), Austronesian Tagalog (Haiman 1978 citing Schachter \& Otanes 1983), and Hebrew (Starr 2014 citing Roger Schwarzschild pc). ${ }^{1}$

Similarly, T-to-C movement can mark counterfactual conditionals in a number of other languages such as Italian, European Portuguese, Romanian, Russian, Bulgarian (Iatridou \& Embick 1994), Breton (Shafer 1995), and Estonian (Külmoja 2005). Conditional inversion may additionally be used to mark indicative conditionals in German, Dutch, Yiddish, Swedish, Icelandic, as well as being used historically in English (Iatridou \& Embick 1994; Bjorkman 2011).

Starr $(2009,2014)$ notes that the vast majority of theories of conditionals fail to say anything about this conditional-interrogative link which he takes this to be a desideratum of a satisfying theory of conditionals. Notably, Starr claims that the if-clause-as-restrictor account (Lewis 1975; Kratzer 1981, 1986, 2012) is "equally fustrated" by these facts (Starr 2014: fn.1), and uses this as motivation to develop a novel semantics for conditionals which is more in line with that proposed for polar questions. The purpose of this short paper is to defend the if-clause-as-restrictor account against this charge. We will suggest that, rather than posing a puzzle for the if-clause-as-restrictor account, the conditional-interrogative link is entirely compatible with it. We provide a formalisation of an idea proposed in Arsenijević (2009). Namely, that conditional antecedents are instances of polar relatives (as opposed to constituent relatives). ${ }^{2}$ The fact that an if-clause or inverted conditional appears to have the internal syntax of a polar question and the external syntax of a free relative or correlative can be taken at face value. The syntax-semantics mapping which results is entirely transparent: what you see is what you get. The proposal rests on the assumption that an interrogative $\mathrm{C}^{0}$ forms a (singleton) set, and free relative formation type-shifts a set-denoting $\mathrm{CP}$ to a definite description of the set's unique (maximal) member. In this case, a polar free relative will be a definite description of a proposition.

1 In addition, Breit (2019) suggests that complementizer distribution in Welsh is best accounted for by assuming that conditional complementizers carry an interrogative feature INT.

2 We do not want to claim that every structure which is interpreted as a conditional antecedent is underlyingly a polar free relative. Indeed, in many languages, conditionals are formed through the presence of verbal morphology (e.g., Turkish) and therefore may not be amenable to a similar treatment. 
Williamson

\section{Syntax-Semantics Mapping}

\subsection{Conditional antecedents as modal restrictors}

Few constructions have received as much interest in the semantics and philosophical literature as conditionals. Within the linguistics literature, possibly the most influential account is the if-clause-as-restrictor account (Lewis 1975; Kratzer 1981, 1986, 2012; Heim 1982; von Fintel 1994). This theory is best summarised by the following oft-cited passage.

"There is no two place if...then connective in the logical forms of natural languages. If clauses are devices for restricting the domains of various operators."

(Kratzer 1986, 2012)

According to this account, conditional if does not have any meaning besides serving to mark a restriction on the domain of a (potentially covert) modal operator. Consider an illustrative example (3) from Heim (1982). On a more traditional account of conditionals, (3) would be true only if all the worlds in which John enters the rooms are such that there is an accessible world in which he trips the switch. On the restrictor account, the antecedent of the conditional serves to restrict the domain of the modal, and (3) will be true only if there exists some accessible world in which John enters the room and John trips the switch.

If John enters the room, he might trip the switch.

In cases where there does not appear to be any modal operator in the matrix clause, it is assumed that the conditional clause restricts a covert epistemic necessity modal $\left(\varnothing_{\square}\right)$. For concreteness, we will simply assume that modal operators contain an additional argument slot for a propositional pronoun which restricts the domain of quantification (with $\mathcal{K}$ being an epistemic modal base function which, given a world argument, returns the set of worlds compatible with what is known by the speaker in that world). ${ }^{3}$

$$
\llbracket \varnothing_{\square} \rrbracket^{w}=\lambda p . \lambda q . \forall w^{\prime} \in \mathcal{K}(w) \cap p: q\left(w^{\prime}\right)=1
$$

While this approach has been highly influential in the linguistics literature, as Starr notes, it does not obviously offer any insight into why conditional antecedents are so often question-like in form. Indeed, conditional if is essentially vacuous on this approach, and its homophony with polar question if appears to be little more

3 For simplicity, we suppress discussion of Kratzer's ordering source as it is not relevant for present purposes and all results carry straightforwardly across. 
than an accident. The aim of the present paper is to suggest that the if-clause-asrestrictor account is entirely compatible with the conditional-interrogative link. In fact, the claim is stronger. Specifically, we claim that treating if-clauses and inverted conditionals as polar free relatives results in an entirely transparent syntax-semantics mapping, provided we adopt the if-clause-as-restrictor account.

The compositional semantics outlined below is straightforward and makes few non-standard assumptions. All of which we take to be advantages of the proposal.

\subsection{Conditional antecedents as adverbial relatives}

In a seminal paper on the syntax of conditionals, Geis (1985) argues convincingly that conditional clauses are adverbial relative clauses. Geis explicitly likens conditional antecedents to adverbial clauses such as when-clauses. This re-conceptualization of conditional constructions as adverbial in nature has proved highly influential. Typically, authors have suggested that the operator-variable configuration involved in conditional antecedents is one of world-binding (Bhatt \& Pancheva 2002, 2006; Haegeman 2010). ${ }^{4,5}$

A puzzling fact for any account which tries to group conditionals with $w h$-free relatives, such as when-clauses, is the ability of the latter but not the former to permit long distance construals (Geis 1970). The following example from Larson (1990) is ambiguous between an 'upstairs' reading on which I saw Mary when she made a claim (5a), and a 'downstairs' reading on which I saw Mary at the time such that she claimed she would arrive at that time (5b).

(5) I saw Mary in New York when she claimed she would arrive.

a. I saw Mary in New York [when ${ }_{1}$ she claimed [she would arrive ] $t_{1}$ ].

b. I saw Mary in New York [when ${ }_{1}$ she claimed [she would arrive $t_{1}$ ] ].

Compare this to conditionals which are unambiguous (Geis 1970; Bhatt \& Pancheva 2006; Haegeman 2010). The example in (6), based on Bhatt \& Pancheva (2002), can only mean that I will leave on the condition of you saying you will leave. It cannot mean that you say you will leave on some condition, and I will leave on that condition.

(6) I will leave if you say you will.

4 Rawlins (2013) also appears to endorse this position (Rawlins 2013: 121-22). However, he nonetheless goes on to employ a Kratzerian semantics.

5 Lycan (1984) treats conditionals as event-relatives. While Lycan's proposal arguably captures the apparent synonymy between if $p, q$ and in the event that $p, q$, it does not straightforwardly account for the conditional-interrogative link discussed in section 1. 
One possible explanation for the unequivocal nature of conditionals is that if-clauses, unlike when-clauses, are not derived via movement (Iatridou 1991). Another explanation is that the relevant operator-variable configuration involved in conditional formation is subject to a locality condition. This is the approach adopted by Bhatt \& Pancheva (2002, 2006), and the approach adopted here. Bhatt $\&$ Pancheva $(2002,2006)$ note that the world variable of the main predicate of a clause must be locally bound (Percus 2000). ${ }^{6}$ Since they treat conditionals as world free relatives, if-clauses are correctly predicted to lack a downstairs reading. We will take a slightly different approach. In sections 2.3.2 and 2.3.3, we propose that the variable abstracted over is a propositional variable which is also abstraced over in forming question denotations. This binding is likewise subject to locality constraints due to reasons of compositionality. This fits with the observation by Haegeman (2010) that polar questions pattern with conditionals with respect to the unavailability of long distance construals. Haegeman's example in (7) only has a reading on which the embedded question concerns his saying as opposed to his leaving.

I wonder if he said he would leave.

The syntax of conditional constructions we assume is as follows. A sentence initial if-clause is base generated in a topic position (Haiman 1978), and provides the antecedent for the pronominal restrictor argument of the modal auxiliary. We follow Iatridou (1994), Izvorski (1996), in treating then as a correlative proform which we assume originates as the restrictor argument to the modal operator in the main clause before undergoing fronting to a position adjacent to the associated relative.

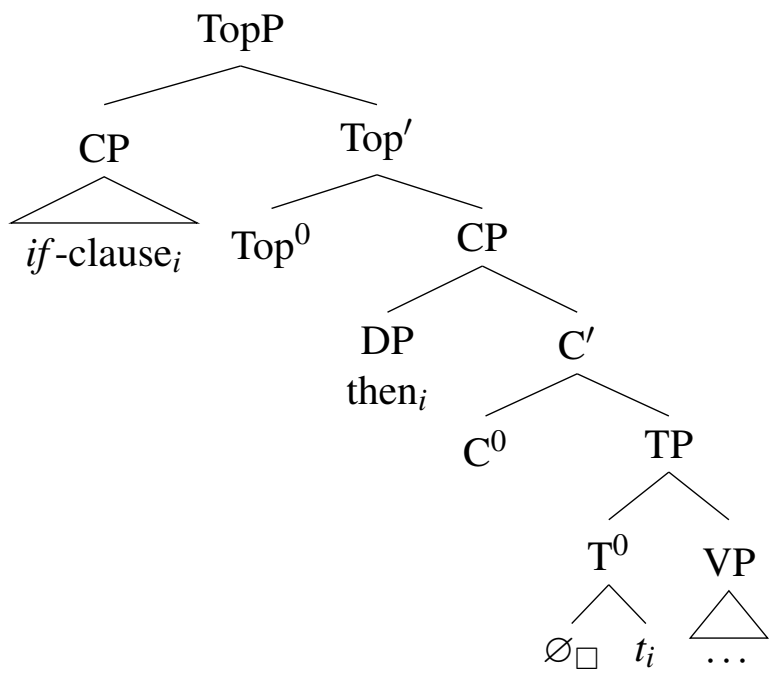

6 This is Percus's (2000) Generalization X. 
Conditional antecedents as polar free relatives

This structure is similar to the syntax proposed in Chierchia (1995) who observes that there appears to be an $\mathrm{A}^{\prime}$-dependency between the antecedent and a position within the main clause (see also von Fintel 1994: 88). In the next section, we will outline the compositional semantics of the if-clause itself.

\subsection{Inside conditional antecedents}

\subsubsection{Free relative formation}

Free relatives are a type of definite description formed from a relative clause (Jacobson 1995; Šimík to appear). It is common to assume that this definite description is derived by a type shifting operation, whereby an $l$ operator is applied to a relative clause picking out the unique (maximal) member of the set denoted by the CP (e.g., Caponigro 2004). Since Geis (1985) explicitly likens if-clauses to when-clauses, we can use when-clauses as a point of reference. We assume that wh-items such as when undergo movement resulting in lambda abstraction, forming a derived predicate (Heim \& Kratzer 1998). In the case of when free relatives, the $w h$-item originates as the complement to a covert temporal preposition AT (e.g., Arregui \& Kusumoto 1998; von Stechow \& Grønn 2013) the resulting structure is a predicate of times at which the event in the relative clause holds. ${ }^{7}$ In (9b), the relative clause is type shifted via an $\imath$ operator, resulting in a definite description of the (maximal) temporal interval at which John sang.

a. [Free Relative when John sang]

b. $\quad \mathrm{CP} \Rightarrow \imath t[\operatorname{sing}(\mathrm{j})$ at $t]$

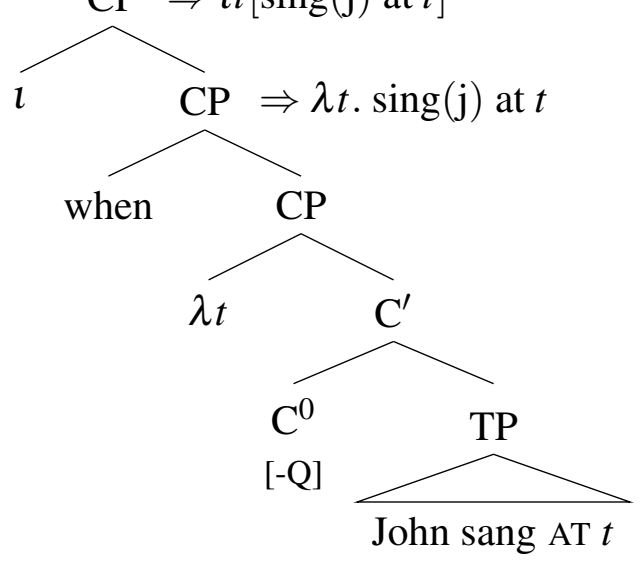

This when-clause can restrict the reference time of the main clause if we assume that tense operators are existential quantifiers with a pronominal domain restriction

7 This is an oversimplification as it underplays the role of (im)perfective aspect. 
argument which may be co-referential with, among other things, when-clauses (Ogihara 1996; Altshuler \& Schwarzschild 2013).

In the following section, we motivate some vital assumptions about polar questions which will allow us to compose polar free relatives in such a way that they can act as restrictors for modal operators.

\subsubsection{Polar question denotation}

Since some of the earliest formal work on the semantics of questions, polar questions were proposed to denote a two-membered set containing the possible answers to the question. Namely, the nucleus proposition and its negation (Hamblin 1973). ${ }^{8}$

$$
\llbracket p ? \rrbracket=\{p, \neg p\}
$$

On this approach to polar questions, they cannot function as a suitable input to free relative formation. However, this approach has not gone uncontested. Many authors have since suggested that polar questions denote singleton sets containing only the nucleus proposition (Bolinger 1978; Biezma \& Rawlins 2012; Krifka 2015).

$$
\llbracket p ? \rrbracket=\{p\}
$$

An immediate problem for a proposal of this sort is in embedded contexts like that in (12). This sentence can be true if it is not raining, and John knows it is not raining. However, if an embedded question only consisted of the positive alternative, it is not clear how (12) would come out as true, since we would appear to need access to the negative alternative.

John knows whether it is raining.

In order to account for the apparent availability of the negative alternative in the case of (12), Biezma \& Rawlins (2012) propose a coercion mechanism which essentially adds the negative alternative to a polar question when it is embedded under such verbs. We can achieve this through a coercion operator like that in (13).

$$
\llbracket \mathrm{Op} \rrbracket=\lambda Q_{<s t, t>} . \lambda p . Q(p) \vee Q(\neg p)
$$

Interestingly, however, the most compelling piece of evidence for the existence of a denotation like that in (11) comes from a similar construction with the dubitative doubt. Specifically, Biezma \& Rawlins note that the embedded polar question in (14a) is interpreted much like a simple that clause (14b).

(14) a. John doubts whether it is raining.

8 For convenience, sets and their characteristic functions will be used interchangeably. 
Conditional antecedents as polar free relatives

b. John doubts that it is raining.

Biezma \& Rawlins suggest that doubt is unable to embed a set denoting complement with a cardinality $>1$. Evidence for this comes from the fact that, while doubt can embed that clauses and whether polar questions, it is unable to embed alternative questions or constituent questions.

a. * John doubts whether or not it is raining.

b. * John doubts when it will rain.

They suggest that if doubt cannot embed questions with more than one alternative, the embedded polar question in (14a) must denote a singleton set, which would also offer an explanation for the apparent equivalence of (14a) and (14b).

We can derive a denotation like that in (11) by adopting the question operator in Fox (2012) and Dayal (2016). The complementizer first combines with TP before taking an additional argument $q$ which is later abstracted over to return the set of propositions $q$ such that $q=p$.

$$
\llbracket \mathrm{C}_{[+\mathrm{Q}]}^{0} \rrbracket=\lambda p \cdot \lambda q \cdot q=p
$$

The addition of the second argument $q$ which is later abstracted over becomes crucial in the derivation of constituent questions. In (17) abstraction over $q$ is necessary in order to form a set of propositions after movement of the wh-item. ${ }^{9}$

a. When did John sing?

b.

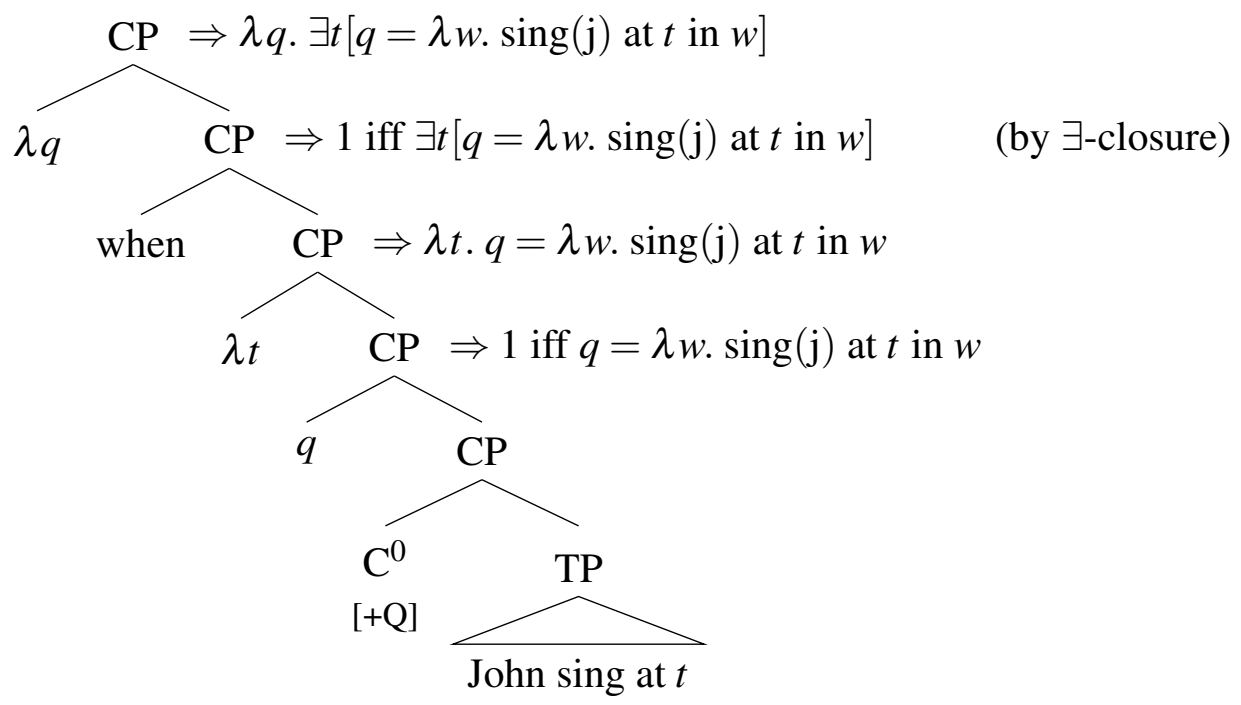

9 Following the tradition of Karttunen (1977), Dayal treats $w h$-words as existential quantifiers. However, in order to maintain a consistent semantics for $w h$-words such as when across questions and relative clauses, we are assuming that question formation involves a step of existential-closure (Heim 1982) after movement of the $w h$-item. 
The question denotation in (17) is (the characteristic function of) the set of propositions $q$ such that there is some time $t$ for which $q$ is the proposition that John sang at $t$. This will be the set of propositions John sang at $t$ for all (contextually relevant) past times $t$ (i.e., the set of possible answers to the question).

\subsubsection{Putting it together}

Given our assumption that the extension of a polar question $p$ ? is the singleton set $\{p\}$, the denotation of a polar free relative will be a definite description of the proposition $p$. The derivation of an if-clause is spelled out in (18b).

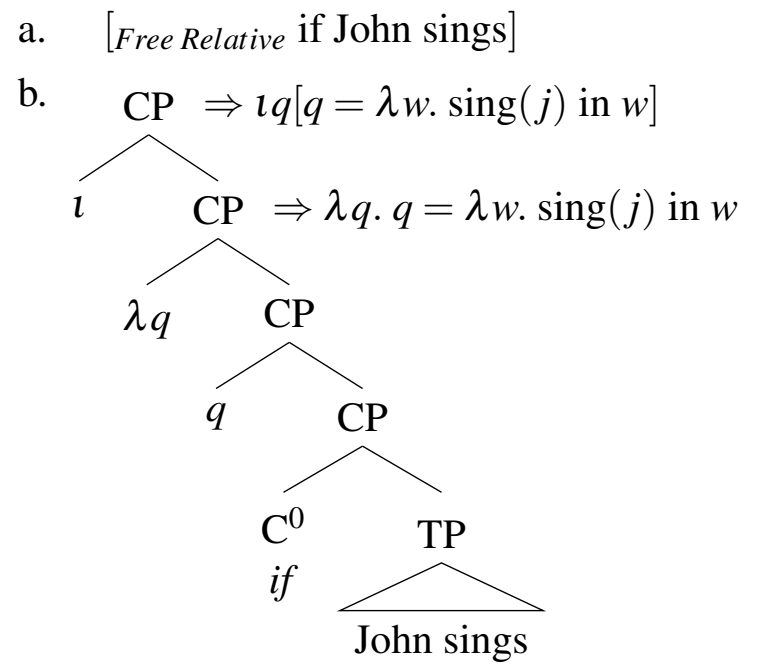

Note that this if-clause is a definite description of a proposition and will serve as the antecedent for the pronominal restrictor argument of the modal operator occupying the main clause. In the case of inverted conditionals, we have essentially the same picture. $\mathrm{A} \mathrm{C}_{[+\mathrm{Q}]}^{0}$ prompts T-to-C movement and creates a singleton set. Subsequent type-shifting returns a definite description of a proposition, and composition proceeds as with canonical if conditionals.

\section{Discussion}

\subsection{Comparison to previous proposals}

The idea that certain conditional antecedents are polar free relatives has some precedence in the syntax literature. Specifically, Arsenijević (2009) and Haegeman (2010) both defend such a position. However, neither provides an explicit syntax-semantics 
Conditional antecedents as polar free relatives

mapping. The present paper may be understood as providing a formalisation of this general proposal. ${ }^{10}$

It is worth comparing the syntax-semantics mapping proposed here to that of Bhatt \& Pancheva $(2002,2006)$. They propose that if-clauses in conditional constructions are world-denoting free relatives, a proposal explicitly inspired by the semantics of conditionals developed by Schlenker (2004) and Schein (2001). In order to arrive at the correct denotation for polar question if-clauses, they assume a covert whether which shifts a proposition $p$ into the set $\{p, \neg p\}$ (Bhatt \& Pancheva 2002). This means that if-clauses do not differ from standard that clauses prior to free relative formation or question formation. This leaves the cross-linguistic tendency for conditional markers to be homophonous with question markers essentially unaccounted for (since it is the covert whether which is doing all the work in forming polar questions). Conversely, on the present account, if has a single semantics in both constructions (question forming) and it is the presence or absence of free relative formation which dictates its status as a conditional antecedent or a polar question.

\subsection{Converging evidence}

In this short paper, we proposed that the role of if was to form a singleton set as a means of explaining how the conditional-interrogative link is compatible with ifclause-as-restrictor theory of conditionals. In recent work, Khoo (Forthcoming) has independently proposed that conditional if is responsible for mapping a proposition to a singleton set containing the proposition. Khoo's motivation is accounting for the interpretation of coordinated conditional antecedents. It is notable that the two proposals have converged on a similar semantics for if in order to account for different sets of facts which are not prima facie connected. The convergence of these proposals is a promising indication that this story is on the right track.

\section{References}

Altshuler, Daniel \& Roger Schwarzschild. 2013. Moment of change, cessation implicatures and simultaneous readings. In Proceedings of sinn und bedeutung, vol. 17, 45-62.

Arregui, Ana \& Kiyomi Kusumoto. 1998. Tense in temporal adjunct clauses. In Semantics and Linguistic Theory (SALT), vol. 8, 1-18.

10 In fact, both authors appear to treat the variable abstracted over as a world variable as opposed to a propositional variable. However, given that neither provides a compositional semantics, it is not clear how integral that assumption is their treatment of conditionals as polar relatives. 
Arsenijević, Boban. 2009. \{Relative \{conditional\{correlative clauses\}\}\}. In Anikó Lipták (ed.), Correlatives cross-linguistically, 131-156. John Benjamins.

Bhatt, Rajesh \& Roumyana Pancheva. 2002. A cross-constructional analysis of if clauses. Handout for Syntax seminar: interface in the CP domain, Zentrum fur Allgemeine Sprachwissenschaft. http://people.umass.edu/bhatt/papers/ bhatt-pancheva-if.pdf.

Bhatt, Rajesh \& Roumyana Pancheva. 2006. Conditionals. In The Wiley Blackwell Companion to syntax, Wiley Online Library.

Biezma, María \& Kyle Rawlins. 2012. Responding to alternative and polar questions. Linguistics and Philosophy 35(5). 361-406.

Bjorkman, Bronwyn. 2011. The syntax of inverted conditional antecedents. Handout for talk at Linguistics Society of America (LSA) 2011.

Bolinger, Dwight. 1978. Yes—no questions are not alternative questions 87-105. Springer Netherlands.

Breit, Florian. 2019. Welsh mutation \& strict modularity: University College London $\mathrm{PhD}$ dissertation.

Caponigro, Ivano. 2004. The semantic contributions of wh-words and type shifts: Evidence from free relatives crosslinguistically, vol. 14, 38-55.

Chierchia, Gennaro. 1995. Dynamics of meaning: Anaphora, presupposition, and the theory of grammar. University of Chicago Press.

Cowan, Marion. 1969. Tzotzil grammar. Summer Institute of Linguistics of the University of Oklahoma.

Dayal, Veneeta. 2016. Questions. Oxford University Press.

von Fintel, Kai. 1994. Restrictions on quantifier domains: University of Massachusetts Amherst PhD dissertation.

Fox, Danny. 2012. The semantics of questions. MIT Class notes. http://lingphil.mit. edu/papers/fox/firstclass.pdf.

Geis, Michael. 1970. Adverbial subordinate clauses in english.: Massachusetts Institute of Technology $\mathrm{PhD}$ dissertation.

Geis, Michael. 1985. The syntax of conditional sentences. Ohio State University working papers in linguistics (OSUWPL) 3. 130-159.

Haegeman, Liliane. 2010. The movement derivation of conditional clauses. Linguistic Inquiry 41(4). 595-621.

Haiman, John. 1978. Conditionals are topics. Language 54(3). 564-589.

Hamblin, Charles. 1973. Questions in montague grammar. Foundations of language 10(1). 41-53.

Heim, Irene. 1982. The semantics of definite and indefinite noun phrases: University of Massachusetts Amherst PhD dissertation.

Heim, Irene \& Angelika Kratzer. 1998. Semantics in generative grammar, vol. 1185. Blackwell Oxford. 
Conditional antecedents as polar free relatives

Iatridou, Sabine. 1991. Topics in conditionals: Massachusetts Institute of Technology $\mathrm{PhD}$ dissertation.

Iatridou, Sabine. 1994. On the contribution of conditional then. Natural Language Semantics 2. 171-199.

Iatridou, Sabine \& David Embick. 1994. Conditional inversion. In North East Linguistic Society (NELS), vol. 24, 189-203.

Iatridou, Sabine \& Hedde Zeijlstra. 2015. If diachronically. Slides of presentation at the 22nd International Conference on Historical Linguistics. Workshop on Patterns and Models of Semantics Change. Naples.

Izvorski, Roumyana. 1996. The syntax and semantics of correlative proforms. In North East Linguistic Society (NELS), vol. 26, 133-147.

Jacobson, Pauline. 1995. On the quantificational force of english free relatives. In Quantification in natural languages, 451-486. Springer.

Karttunen, Lauri. 1977. Syntax and semantics of questions. Linguistics and philosophy 1(1). 3-44.

Kayne, Richard S. 1991. Romance clitics, verb movement, and PRO. Linguistic inquiry 22(4). 647-686.

Khoo, Justin. Forthcoming. Disjunctive antecedent conditionals. Synthese http: //www.justinkhoo.org/DA-rev-final.pdf.

Kratzer, Angelika. 1981. The notional category of modality. In Hans-Jürgen Eikmeyer \& Hannes Rieser (eds.), Words, worlds, and contexts: New approaches in word semantics. berlin: W. de gruyter, 39-74.

Kratzer, Angelika. 1986. Conditionals. Chicago Linguistics Society 22 (2). 1-15.

Kratzer, Angelika. 2012. Modals and conditionals: New and revised perspectives. Oxford University Press.

Krifka, Manfred. 2015. Bias in commitment space semantics: Declarative questions, negated quetions, and question tags. In Semantics and Linguistic Theory (SALT), vol. 25, 328-345.

Külmoja, Irina. 2005. Conditional constructions in Estonian. In Victor Xrakovskij (ed.), Typology of conditional constructions, chap. 11, 390-415. LINCOM Europa.

Larson, Richard. 1990. Extraction and multiple selection in PP. The Linguistic Review 7(2). 169-182.

Lewis, David. 1975. Adverbs of quantification. In E Keenan (ed.), Formal semantics of natural language, 3-15. Cambridge university press.

Lycan, William. 1984. A syntactically motivated theory of conditionals. Midwest Studies in Philosophy 9(1). 437-455.

Ogihara, Toshiyuki. 1996. Tense, scope and attitude ascription. Kluwer.

Percus, Orin. 2000. Constraints on some other variables in syntax. Natural language semantics 8(3). 173-229. 
Rawlins, Kyle. 2013. (un)conditionals. Natural language semantics 21(2). 111-178. Schachter, Paul \& Fe Otanes. 1983. Tagalog reference grammar. University of California Press.

Schein, Barry. 2001. Adverbial, descriptive reciprocals. In Semantics and linguistic theory, vol. 11, 404-430.

Schlenker, Philippe. 2004. Conditionals as definite descriptions. Research on language and computation 2(3). 417-462.

Shafer, Robin. 1995. Negation and verb second in Breton. Natural Language and Linguistic Theory 13. 135-172.

Šimík, Radek. to appear. Free relatives. In Matthewson Lisa Cécile Meier Rullmann Hotze Zimmerman Thomas Gutzmann, Daniel (ed.), Semantics companion, Wiley-Blackwell. https://semanticsarchive.net/Archive/WQ0YWRIM/ simik2018FRsemcom.

Starr, William. 2009. Conditionals and questions. Manuscript, Rutgers University . Starr, William. 2014. What 'if'? Philosophers' imprint 14, no.10. 1-27.

von Stechow, Arnim \& Atle Grønn. 2013. Tense in adjuncts part 2: Temporal adverbial clauses. Language and Linguistics Compass 7(5). 311-327.

Gregor Williamson

UCL Department of Linguistics

Chandler House

Wakefield Street

London, WC1N 1PF

gregor.williamson.14@ucl.ac.uk 